\title{
The Analysis on the Effecting Factor of Drought Disease in Qingyang, Gansu
}

\author{
Xiaodong Wang \\ The College of Mine and Coal, Inner Mongolia University of Science and Technology, Baotou \\ 014010, China
}

Received 4 December 2015

Accepted 15 March 2016

\begin{abstract}
In recent years, the global climate is becoming warmer and warmer. The discussion about the global warming effecting on is also more and more intensified. The paper analyzes change of air temperature and precipitation change occurred from last half century to the beginning of this century in the Qingyang region, Gansu Province, China. Considering the relation between El-nino, La-nina and drought disease, we want to find out the reason of drought disease under the global warming, and to contribute to the theory studying of relieving poverty. The analysis and concluding is that drought disease is worse and worse in the region, air temperature and precipitation is negative correlation obviously, the rising of air temperature is main reason of drought disease.
\end{abstract}

Key Words: Global warming, Precipitation change, Drought disease, El-nino, La-nina, Qingyang

\section{甘肃庆阳地区旱灾发生的气候影响因素分析 \\ 王晓冬 \\ 内蒙古科技大学矿业与煤炭学院, 包头 014010 , 中国}

摘要: 近年来, 全球气候变暖已经成为不争的事实, 针对气候变暖所带来影响的讨论成 为一个热点。本文通过分析上世纪中期至本世纪初的 50 年间甘肃庆阳地区的气温、降水变化 趋势及厄尔尼诺、拉尼娜事件与干旱气候的关系, 试图探讨全球气候变化下本区干旱的情况及 其产生原因, 为减轻本区由此产生贫困的问题提供理论依据。分析认为: 甘肃庆阳地区干旱情 况有越来越严重的趋势, 本区降水与气温存在着明显的负相关性。这说明气温的升高是干旱发 生的主要因素之一，厄尔尼诺及拉尼娜事件与干旱的发生也有一定的关系。

关键词: 全球气候变暖; 降水变化; 干旱; 厄尔尼诺; 拉尼娜; 庆阳地区 
随着全球气候的日益变暖, 极端天气现象 频发, 在这之中, 地区降水变化的不均衡表现 得尤为突出, 不仅是国家与国家之间降水变化 不均衡，即使在同一国家内部，不同地区之间 降水变化的不均衡性表现得也相当明显。拿中 国来说，常常是北方大旱的同时南方则连续洪 涝，因此分析全球气候变化对不同地区的影响 对预防极端天气变化, 减少自然灾害发生所带 来的生命和财产等损失有着重要意义。

甘肃庆阳地区是陕甘宁革命老区重要组 成部分, 又是全国著名的国家级贫困地区，全 区具有典型的黄土高原地形、地貌，是典型的 旱作农业区, 由于地表水的缺乏, 农业生产对 大气降水依赖程度比较高。随着全球气候的变 化, 本区干旱程度的变化日益明显, 严重影响 并制约着本区的农业生产。为配合国家新的五 年计划中关于扶贫工作的安排部署, 分析造成 干旱的气候影响因素对本区发展农业生产、摆 脱贫困、实现国家战略目标有着重要意义。本 区位于甘肃省东部, 介于 $10645^{\prime}-10845 \mathrm{E}$ 与 $3510^{\prime}-3720^{\prime} \mathrm{N}$ 之间, 辖区有西峰、庆阳、镇 原、宁县、正宁、合水、华池和环县七县一市, 包括 146 个乡镇, 1488 个行政村, 11064 个自 然村, 总人口约 251.46 万，其中农业人口 223.75 万 $^{[1]}$ 。本区是陇东黄土高原的重要组成 部分, 有典型的黄土高原沟壑、丘陵地貌。辖 区农业人口占总人口比重 $90 \%$ 以上, 农业是当 地支柱产业, 但年平均降雨量在 480-660mm, 全区 92\%的耕地为旱作农业, 因此对环境的依 赖程度较高。2000年的农民人均纯收入为 1272 元 1999 年的农民人均纯收入为 1380 元，农民 收入仍然受自然灾害影响 ${ }^{[1]}$ 。全区人均 GDP 为 2278 元仅占全国和全省平均水平 $32.4 \%$ 和 $57.9 \%$, 社会经济的总体发展水平仍相当落后 [2]。本区 8 个县市中就有一个国家级贫困县和 一个省级贫困县, 因此如何尽早摆脱贫困, 对 完成国家未来几年的经济发展目标有着重要 意义。而气候变化对农业的影响是首当其冲的 重要指标, 特别是全球气候变化下日益干旱的 特点严重制约着本区农业发展, 如何根据气候 变化规律和干旱情况指导农业发展, 积极预防 和应对也是行之有效的办法之一。

\section{1. 数据与分析方法}

通过对甘肃庆阳地区西峰、庆阳、镇原、 宁县、正宁、合水、华池和环县 8 个县市由 1951
到 2000 年降水情况的分析, 对比本区气温变 化趋势与厄尔尼诺及拉尼娜现象发生规律, 寻 找干旱与气温和极端事件之间的关系, 分析干 旱发生的影响因素, 为本区经济发展提供理论 依据。

\section{2. 干旱情况日益加剧}

\section{1 年降水量逐年减少}

据 1970 至 2005 年降水数据绘制时间序列 图（图 1) 可知, 本区年降水量呈逐年减少的 趋势, 且降幅较大, 表明干旱程度加剧。且通 过相关分析可知, 降水变化与年份存在正相关 且相关系数较高, 表明降水量减少与时间变化 的相关性明显。

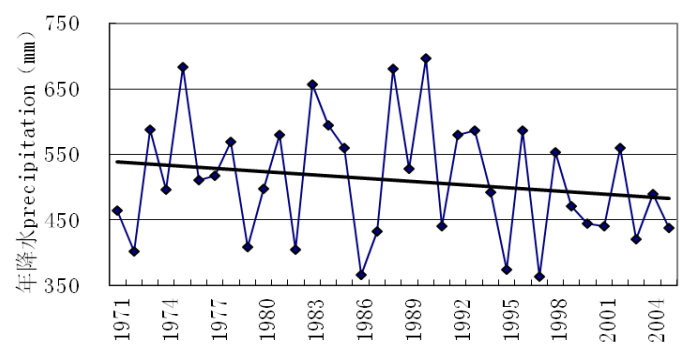

图 1 庆阳地区年降水变化趋势

Fig. 1 The yearly average precipitation change of

Qing-yang region

\section{2 四季降水变化不均衡}

利用庆阳地区春、夏、秋、冬四季降水统 计数据作趋势图(图 2-5)分析可知, 春季, 本区 降水减少但趋势不明显, 降水随时间的相关系 数 $\mathrm{R}=0.0003$, 表明几十年来春季的干旱情况随 时间变化的影响不大。

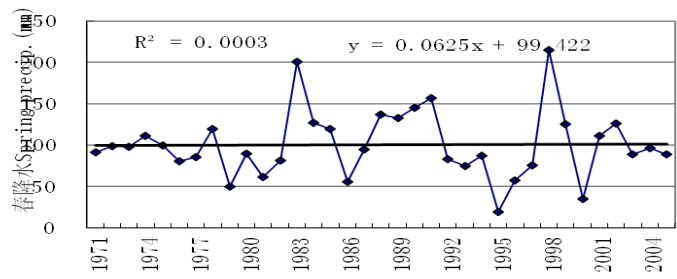

图 2 庆阳地区春季降水变化趋势

Fig.2 The spring season average precipitation change of Qing-yang region 


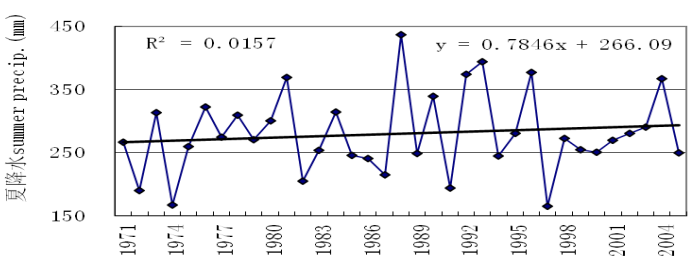

图 3 庆阳地区夏季降水变化趋势

Fig.3 The summer season average precipitation change of Qing-yang region

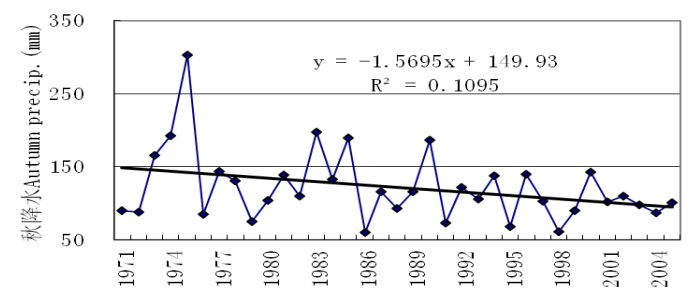

图 4 庆阳地区秋季降水变化趋势

Fig.4 The autumn season average precipitation change of Qing-yang region

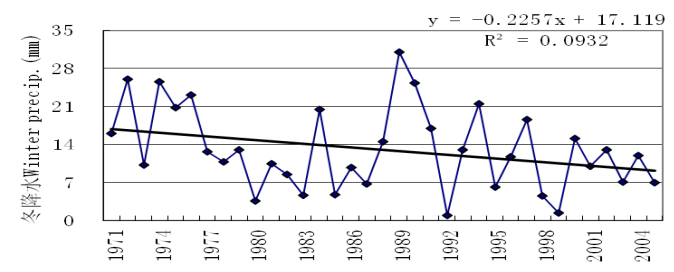

图 5 庆阳地区冬季降水变化趋势

Fig.5 The winter season average precipitation change of Qing-yang region

夏季, 与春、秋、冬三季降水逐渐减少的 趋势不同, 夏季降水呈明显上升趋势, 且增幅 较大, 相关系数 $\mathrm{R}=0.0157$, 相关性明显。表明, 夏季降水随时间变化有明显增加的趋势。

秋季降水呈大幅下降趋势, 下降幅度为每 年 1.56 毫米, 相关系数较大为 0.1095 , 表明降 水随时间变化下降幅度相当明显, 且两者相关 性很大。

冬季降水也呈明显下降趋势, 下降幅度为 每年 0.23 毫米, 相对秋季降水下降情况来看, 虽然总体下降幅度没有秋季大, 但相对而言, 其下降情况也较严重。
由以上分析可知, 四季当中, 春季降水趋 势保持平稳, 降幅不大, 夏季降水不仅没有减 少反而呈现升高的趋势, 且升高幅度较大, 秋 冬两季降水明显呈下降趋势且幅度较大, 表明 四季降水变化趋势不均衡。

本区由于主导产业为农业, 所以降水的季 节分配对本区经济影响较大, 总体来讲, 夏季 降水量的增加一定程度上对本区农作物生长 有一定的好处, 但夏季降水的增长幅度为每年 0.78 毫米, 虽然增长幅度较大, 但相对秋冬两 季总共的减少幅度为 1.79 毫米而言, 总体全年 降水仍呈现巨大的减少趋势, 由此表明本区降 水逐年减少，干旱情况日益严重。

除全年降水量的多寡对农业生产有较大 影响外, 年内的四季降水分配情况也对农作物 的生长影响较大。中国是典型的季风气候, 在 气温和降水的组合分配过程中水热同期的组 合特点一定程度上有助于农作物生长, 也就是 说, 夏季气温最高同时夏季又是一年中降水量 最大的季节对作物生长是有好处的, 同时夏季 的降水有逐年增加的趋势对本区农耕经济有 力。但同时秋冬季降水急剧减少, 会使土壤含 水量大量减少, 而春季降水又不足以弥补损 失, 使土地墑情受到严重影响, 因此要想弥补 由于秋冬降水减少所带来的影响, 如何改善农 业耕种制度也是刻不容缓的工作。

\section{3 降水距平值为负的年份较多}

根据年降水低于平均值的情况将 1954 年 至 2000 年年降水与年均降水量之差绘制降水 距平图 (图 6) 可知, 距平值为负值的年份较 多, 且有些年份甚至低于 $-20 \%$ 。

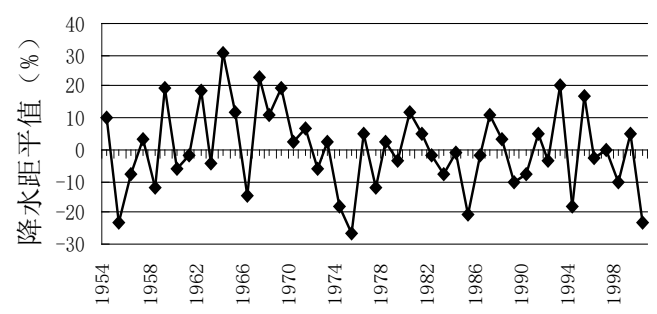

图 6 庆阳地区降水距平变化

Fig.6 The comparing yearly average precipitation change of Qing-yang region 
根据降水距平变化情况 (图 6) 可以看出, 庆阳地区降水低于平均值的干旱年份较多, 特 别是上世纪 90 年代以来, 低于平均值的年份 有增加趋势。表明本区降水量有逐年减少的趋 势，而干旱情况则日益严重。对从 1950 年至 2000 年的降水距平为负值的年份做统计分析, 绘制负距平年份图表（表 1)，可以看出，50 年间降水负距平的年份共有 17 年次, 尤其是 进入 70 年代以来干旱年份更多、更加频繁， 其中低于-20\%的极端干旱年份共有 5 年, 分别 是 1974、1975、1985、1994、2000 年。

\section{表 1 庆阳地区降水距平为负值 (干旱) 的年份}

Tab.1 Years of precipitation difference is below 0 (drought disease)

\begin{tabular}{|c|c|c|c|c|c|c|}
\hline \multicolumn{7}{|c|}{ 年代 甘肃庆阳 } \\
\hline 50 & 1955 & 1956 & 1958 & & & \\
\hline 60 & 1960 & 1961 & 1963 & 1966 & & \\
\hline 70 & 1972 & 1974 & 1975 & 1977 & 1979 & \\
\hline 80 & 1982 & 1983 & 1985 & 1989 & & \\
\hline 90 & 1990 & 1992 & 1994 & 1996 & 1998 & 2000 \\
\hline
\end{tabular}

\section{3. 庆阳地区干旱发生的因素分析}

3.1 气候变暖是干旱发生的主要因素之一

根据甘肃庆阳地区 1970 到 2005 年间的气 温变化情况分析（如图 7)，气温总体呈上升 趋势, 其线性方程为: $Y=0.042 X+8.391$, 表明 气温以每年平均 0.042 的速度递增, 远高于全 球平均增温幅度 $0.03^{\circ} \mathrm{C} /$ 年。相关系数 0.697 , 所以变暖的趋势很明显。

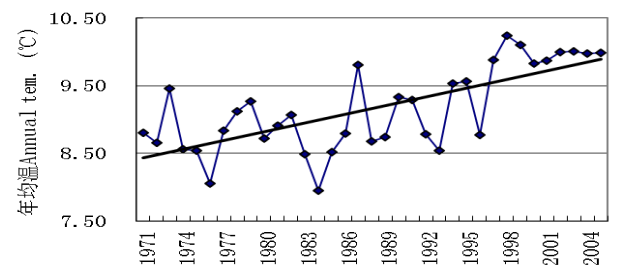

图 7 庆阳地区 1970-2005 年平均气温变化图

Fig.7 The yearly average temperature change of Qing-yang region

世界气候变化越来越受到关注,有一点是 公认的, 即近百年来气候存在着明显增温的趋 势。政府间气候变化委员会 (IPCC) 指出近百 年来气候增温约 $0.5^{\circ} \mathrm{C}$ 区 $^{[3]}$, 其第三次评估报 告指出, 20 世纪全球平均温度升高 $0.6 \pm 0.2^{\circ} \mathrm{C}$, 80 年代和 90 年代是近 100 年来最温暖的 20 年 ${ }^{[4]}$ 。据专家推测, 如果目前温室气体排放趋
势继续下去, 地球表层将以 $0.3^{\circ} \mathrm{C} / 10 \mathrm{a}^{[5]}$ 的速 度增温。

气候变暖对降水量分布及多寡变化的影 响以及由此产生的一系列对农业生产带来的 后果问题, 长期以来一直是人们关注的焦点, 许多学者在做了大量分析研究的基础上纷纷 提出自己的观点, 一般认为, 气候变暖后降水会 变得更加干燥和不稳定 ${ }^{[6]}$ 。气候变暖很大程度 上会引起干旱的发生从而影响农业生产。在我 国, 西北、华北和东北大部分地区是增温最显 著的地区 ${ }^{[7]}$ 。Kellogg 认为中国主要农业区很可 能变干旱, 对粮食生产有严重影响 ${ }^{[8]}$ 。

美国学者 Parry 和 Swaminathan 也指出, 全球升温将使中国北方和华中的土壤水分减 少, 农业减产[9]。还有人认为: 全球变暖将导 致世界主要粮食产区的中纬度和大陆中部地 区将变干旱 ${ }^{[10]}$, 国外实验也表明, 对于生长季 节来说, 在气温升高 $1^{\circ} \mathrm{C}$ 的情况下, 灌溉需求 增加 $12 \%$, 易发生旱灾 ${ }^{[11]}$ 。

因此伴随着全球气候变暖本区气温也呈 现了上升趋势, 并且与此同时随着本区气温总 体上升干旱情况也越来越严重, 干旱的发生又 直接影响农业生产, 而本区农业占经济收入的 过高比重也最终成为本区贫困发生的重要因 素。

\section{2 四季气温均升高但增幅不同}

根据本区四季气温数据资料做趋势分析 (如图 8-11) 可知, 春、夏、秋、冬四季气温均 呈现增加趋势, 表明在年均温逐年上升的同 时, 四季气温也呈现出逐年上升的趋势, 但明 显增温的幅度不同, 其中秋季增温幅度最小, 而冬季增温幅度最大。且相关系数也最大, 表 明年均温的逐年增加最主要的表现在冬季气 温随时间变化增加趋势最大的基础上。

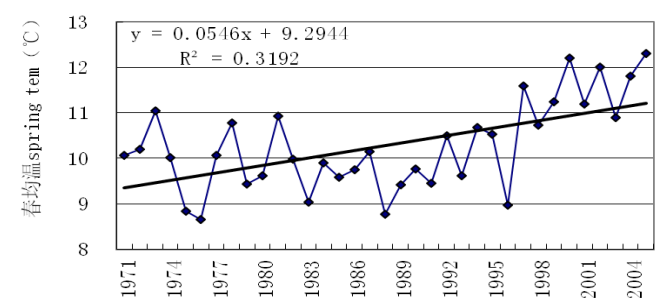

图 8 庆阳地区春季气温变化趋势

Fig. 8 The spring season average temperature change of Qing-yang region 


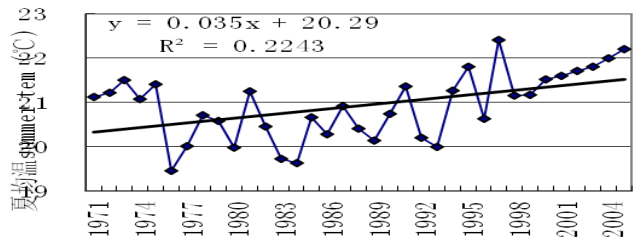

图 9 庆阳地区夏季气温变化趋势

Fig.9.The summer season average temperature change of Qing-yang region

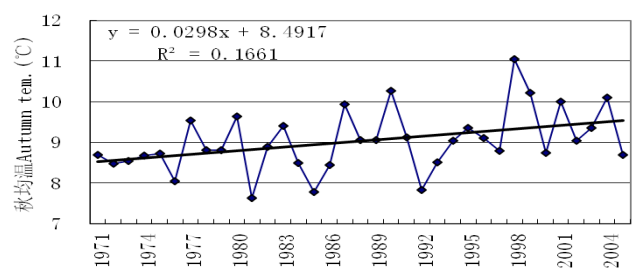

图 10 庆阳地区秋季气温变化趋势

Fig.10 The autumn season average temperature change of Qing-yang region

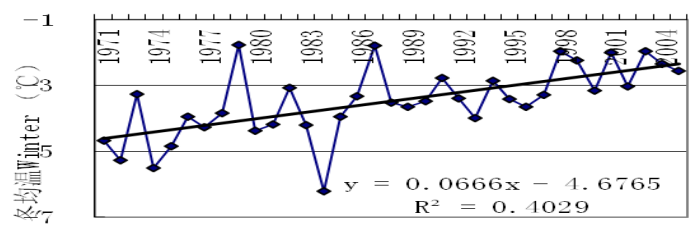

图 11 庆阳地区冬季气温变化趋势

Fig.11 The winter season average temperature change of Qing-yang region

对比降水的季节变化, 气温的季节变化一 方面有助于农作物生长, 特别是夏季气温升高 的同时夏季降水不减增, 雨热同期对本区的早 作农业有一定好处。但另一方面, 秋冬季气温 特别是冬季气温增加最明显的同时秋冬季降 水却大幅度减少, 其中冬季降水减少幅度最 大。这种水热组合状况必然会对农业产生一定 影响。俗话说, 麦收隔年墑, 秋冬季的升温会 加剧土壤水分蒸发, 同时秋冬季降水又呈现下 降趋势, 这就使得保存在土壤中的水分锐减, 而本区属于黄土高原地形地貌，地表水、地下 水相对较少, 农业生产更多依靠大气降水, 虽 然秋冬季的土壤干旱不会给农作物造成较大 影响, 但来年开春, 由于春季升温的同时降水 量并没有增加的趋势, 使得秋冬季土壤损失的 水分不能及时得到有力的补充, 所以极易造成
春旱, 而同时春季正是作物出苗、分藥等重要 时期, 所以会对农业产生较大影响从而影响本 区经济的经济发展。

本区现有的农作物从成熟季节来看有夏 熟和秋熟两种, 夏熟作物主要指三月播种六月 收割的春小麦, 或是可越冬来年六月收割的冬 小麦, 秋熟作物指春季播种秋季收割的粮食作 物如玉米、马铃薯和油料作物如胡麻等。从水 热组合情况来看, 夏季的雨热同期更适合秋熟 作物的生长, 而夏熟作物因为成长季主要集中 在春季和夏初, 而此时夏季降水还没有充分来 临, 上一年的秋冬季暖而干的气候已经使土壤 储存水分大量蒸发, 且春季降水变化不大, 又 使得没有充足的降水进行弥补, 所以土壤处在 严重缺水期, 因此夏熟作物不能很好生长。所 以如何改变耕种制度也是应对气候变化, 提高 农业生产, 实现脱贫致富目标的主要途径之 一。

\section{3 气温与干旱的关系}

利用庆阳地区 1950 年至 2000 年降水数据 资料作两者的相关趋势分析（如图 12）可知, 二者呈明显负相关性, 其中线性方程为 $\mathrm{Y}=-58.432+1046$ 且相关系数较高 $\mathrm{R}=0.1574$, 表明本区气温升高的同时降水明显较少, 即暖 干现象明显。说明气温的变化是造成本区干旱 的主要原因之一。

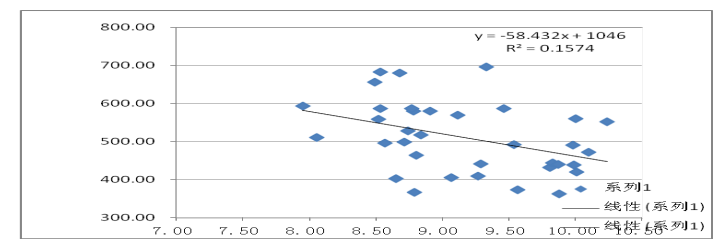

图 12 庆阳地区降水与气温变化关系

Fig. 12.The relation of precipitation and temperature change of Qing-yang region

\section{4 气候极端事件与干旱的关系}

气候极端事件是指某一地点或地区从统 计分布的观点来看不常有或极少发生的天气

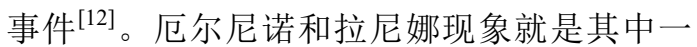
种。厄尔尼诺又称南方涛动, 主要指在东南太 平洋与印度洋及印尼地区之间的反相气压振 动, 是一种海水偏暖对大气产生影响的海气互 动现象。拉尼娜则与之相反, 是由于海水温度 
偏低所导致的气候异常。这两种事件的出现常 常引起世界范围的气候异常, 表现为使大陆夏 秋两季降水分布南北不均, 易出现南涝北旱现 象 ${ }^{[13]}$ 所以 2002 年前后长江流域应重点防御 重大洪涝灾害，而华北、特别是西北地区应重 点防御重大旱灾的发生 ${ }^{[14]}$ 。

据世界气象组织的报道: 1951 到 2000 年 间，厄尔尼诺发生了 14 次，发生年代分别为 1953、1957 1958、1963、1965 1966、1969、 1972 1973、1976、1982 1983、1986 1987、 1991 1992、1993、1994 1995、1996、 1997 1998, 由此可以看进入 90 年代以来厄 尔尼诺发生频繁且具有持续时间长、间隔时间 短的特点 ${ }^{[12]}$ 。厄尔尼诺年及拉尼娜年世界气候 变化较大, 极易引起降水的地区分配异常, 导 致局部地区涝灾、旱灾频繁发生, 如 1998 的 厄尔尼诺年, 我国长江流域、嫩江、松花江流 域出现特大涝灾。而此时甘肃庆阳地区却面临 旱灾的威胁 ${ }^{[15]}$ 。在上世纪后 50 年以来的 14 次 厄尔尼诺年中, 降水量低于平均值的年份有 12 次：1958、1963、1966、1972、1982、1983、 1986、1992、1993、1994、1996、1998。由以 上分析表明, 厄尔尼诺及拉尼娜发生年份庆阳 地区旱灾发生严重, 厄尔尼诺及拉尼娜与本区 旱灾有明显的相关性。

\section{4. 结论:}

(1) 本区气温在升高的同时降水总体减少, 暖干化趋势明显。

(2) 全球气候变暖是影响本区干旱频繁发生 的主要原因。

(3) 厄尔尼诺年、拉尼娜年是旱灾的多发期, 且厄尔尼诺、拉尼娜连续发生年份, 旱情 严重。

\section{参考文献}

[1] 庆阳年鉴编纂委员会.庆阳年鉴, 2001 .
[2] 周立华等.庆阳地区农村生态经济发展模式与政 策建议.干旱地区农业研究，2002，3.

[3] J.T. Houghton, L.G. Meira Filho, B.A. Callander, et al. (eds.), Climate Change 1995: The Science of Climate Change (Cambridge University Press, Cambridge, 1996).

[4] 高峰, 孙成权, 曲建升. 全球气候变化的新认识 ---IPCC,第三次气候评价报告第一工作组报告 概要. 地球科学进展, 2001, 16(3):442-445

[5] 蔡运龙, S. Marry. 全球气候变化下中国农业的 脆弱性与适应对策. 地理学报, 1996（3）: 202-210.

[6] 延军平等.跨世纪全球环境问题及行为对策. 北 京: 科学出版社, 1999, 50-51.

[7] 丁一汇, 戴晓苏.中国近百年的温度变化. 气象 学报, 1994, 20(2): 19-26.

[8] W.W. Kellogg, Mankind's impact on climate: the evolution of an awareness. Climatic Chang, 1987, 10(2), 113-136.

[9] M.L. Parry, M.S. Swaminathan, Effects of Climate Chang On Food Production (Cambridge University Press, Cambridge, 1992).

[10] 蔡运龙等.全球气候变化下中国农业的脆弱性 与适应对策. 地理学报, 1996, 3.

[11] 谢南金. 中国西北干旱气候变化与预测研究. 第三卷, 北京: 气象出版社, $2000,339-344$

[12] 丁一汇, 张锦, 宋亚芳. 天气和气候极端事件的 变化及其与全球变暖的关系. 气象，28（3）, 3.

[13] 赵振国. 厄尔尼诺现象对北半球大气环流和中 国降水的影响.大气科学, 1996,20(4), 422-428.

[14] 栗珂, 刘耀武, 杨文峰, 徐小红, 郑小华.EL Nino 事件的概率预测研究. 热带气象学报, 2001, 05-25.

[15] 王晓冬, 李瑞英.20 世纪 50 年代以来陕甘宁地 区旱情分析. 内蒙古师范大学学报 (自然科学汉 文版），2008，07-15.

\section{作者简介}

王晓冬, (1969-), 女, 内蒙古包头人, 内 蒙古科技大学副教授, 硕士, 研究方向为区域 资源与灾害。

与灾害。 